\title{
Inclusive Design and Mental Health: Policy and legislation challenges from the perspective of social inclusion
}

\author{
E. Chrysikou
}

\begin{abstract}
Mental illness incorporates a spectrum of diseases affecting globally an increasing population over the years to come. Yet, society is still accepting the institutional concept of allocating the risk associated with mental illness to closed institutions. The allocation of closed institutions as the places of treating and caring for mental illness, prevents architecture as well as the rest of the design community of seeing mental health issues as part of a community integrated design concept. On the contrary, design for mental health could form part of a more and more active dialogue of incorporating the needs of mentally ill people in the broader discussion of accessibility and its implications. As this is a very big and with complex topic, this paper will focus on one aspect of the architectural specifications: the buildings use, and how change of legislation towards more flexibility could affect the whole de-institutionalisation prospects of a context. It also includes a Case study of the Hellenic mental health facilities planning legislation and how alterations on the change of use legislation for psychiatric facilities could affect their integration outcome.
\end{abstract}

\section{Background}

Mental illness incorporates a spectrum of diseases affecting globally an increasing population over the years to come. According to WHO, in Europe, almost $20 \%$ of the burden of disease relates to mental illness that affects one in four people at some time in life. Moreover, 9 out of 10 countries with the highest suicide rates in the world are in Europe (WHO 2013). Yet, society is still accepting the institutional 
concept of allocating the risk associated with mental illness to closed institutions, despite the very limited evidence on their therapeutic effectiveness, even if these are small scale facilities (Priebe et al 2005, Chrysikou 2014, Gilburt et al 2014). Europe that is pioneer in the treatment and care of mental illness, is as a whole at the early stages of de-institutionalisation, with the majority of the mentally ill people treated in institutions rather than in the community, providing limited access to services and employment as well as a very small recognition of the contribution of carers (The Economist Intelligence Unit 2014). The fact that mental illness is treated in closed and often segregated from the urban grid institutions, even if they are small in scale and considered part of what is called Community Care, is on the other hand contradictory to advancements in Social Psychiatry that happened as early as in 1932, by the Soviet Government that after building small community projects, established an equivalent of what would nowadays be called a day hospital (Madianos 1980, Vostanis 1989), or even earlier by occupational therapy developments in Germany at 1929. Soon after the war, Foyer Elan Retrouve was developed by Sivadon and in the US, the Movement for Mental Health in the Community was formed, setting the ground for de-institutionalisation (Diebolt 1997, Chartocolis 1989). Since then, WHO directs that mentally ill people should be primarily treated as close to home as possible with hospitals being the last resort (WHO 2001, WHO 2005).

The allocation of closed institutions as the places of treating and caring for mental illness, prevents architecture as well as the rest of the design community of seeing mental health issues as part of a community integrated design concept. On the contrary, design for mental health could form part of a more and more active dialogue of incorporating the needs of mentally ill people in the broader discussion of accessibility and its implications. As this is a very big and with complex topic, this paper will focus on one aspect of the architectural specifications: the buildings use, and how change of legislation towards more flexibility could affect the whole de-institutionalisation prospects of a context. It will also include a Case study of national mental health facilities planning legislation and how alterations on the change of use legislation for psychiatric facilities could affect their integration outcome.

\section{The need to incorporate mental health in the accessibility discussion}

Design for people with disabilities is gradually incorporated into generic architectural guidelines and briefing documentation leading to an increasingly 
Inclusive Design and Mental Health: Policy and legislation challenges from the perspective of social inclusion

integrated built environment. Specifications for people with disabilities start to influence broader architectural typologies, as opposed to specialised accommodation and healthcare facilities only, driven by demographic changes (Langdon et al 2014). Moreover, design requirements for people with mobility problems, visual or other sense-related impairments have already been included in the generic building guidelines and briefs, even if there is still progress to be achieved in areas such as employment (Gomez et al 2014). Strategies and provisions for older people appear in generic policies and architectural guidelines, incorporating those 'designing-forolder-people' frameworks in briefs and requirements of more generic schemes, such as social housing, shops or even entire communities with greater integrating perspectives (Chrysikou et al 2014, Dementia Friendly Hampshire toolkit 2012, Nina Glasgow 2000, Alzheimer's Society report 2013).

This shift in architectural thinking and its effect on the built environment, eventually leads to a more integrated society. So, the discussion on accessibility nowadays involves broader parts of our everyday life, such as accessible education, employment, tourism etc (Darcy et al 2009, Maisel 2010, Riley 1999). People with physical disabilities and sensory impairments as well as older people are gradually viewed from an inclusive perspective, as human capital with diverse benefits for society. There are, for instance, frequent references on the consumer power of babyboomers and their ability to create trends and influence the market (Wu et al 2014, Synchrony financial 2014). This inclusive thinking might be occasionally so powerful that we can see an occasional shift of the argument to addressed positive aspects deriving from dealing with disability. For example, Zeisel identified the value for all of us of learning to experience life in the present tense trough caring or just being involved with people with Alzheimer's (Zeisel 2010).

Continuing to explore encouraging perspectives of inclusion, we will travel back at the onset of historical years. Then, Greeks perceived mental illness as a "Godsent" condition. Mentally ill people were considered to be speaking the voice of Gods. This attribute could be viewed as society introducing through mental illness an element of out of the box-thinking for its unpredictability and its disconnection from common logic and social norms. This God-sent perception of the illness stopped when St Augustin around the $4^{\text {th }}$ Century AD from the theological perspective started a discussion on the relation of demons to mental illness, a relation that was confirmed by the Church two centuries late, leading to Malleus Maleficarum just before the $16^{\text {th }}$ Century (Georgiou et al 1993, Chartocolis 1989).

Since, despite some exceptions such as the Quaker movement, mental illness is still dealt as a problem that society cannot manage in an integrated way. When nonmentally ill people get to a hospital with cabs or ambulances, mentally ill people still in many parts of the western world arrive at the hospital cuffed in a police car. Similarly, for people with disabilities society tries to improve their mobility at home 
and at the same time make the public domain accessible for them to integrate. For acute mentally ill under section though, i.e. the majority of people in acute mental health wards and also for all forensic patients, there is no option to visit the garden of their ward if that is not secure enough (Chrysikou 2013). The reasons could vary, from limitations of Psychiatry to provide until now successful diagnostic and treatment instruments or the reality of harm and self-harm, to the stigma or maybe, even less obvious undercurrents such as the challenging of reason and of social formation (Foucault 1972, Marcus 1993).

This uncertainty related to the perception and understanding of mental illness reflects on the ways societies deal with it. Variety is very much present in the means and methods that are employed for its treatment: from a plethora of complex systems and webs of specialised facilities with varying degrees of control in Western countries to just chains on barks of trees and the absence of any form of shelter in countries such as Somalia (WHO 2010). Yet, there is a common denominator in all these attempts that on all other aspects present so many differences that direct analogies have limited value. It is what Psychiatrists call dangerousness (Chiswick 1995) and the inability yet of society to accept containing the risk associated with mental illness.

In short, here lies an important difference between mental illness and other disabilities regarding inclusive design. In the latter, society accepts to contain the risk, which is mainly for the individual rather than for society, explores ways for its management, with accessibility policies being one of those. This leads eventually to the facilitation of integration of vulnerable groups, such as older people, people with sensory impairments or people with mobility problems. In mental illness however, the closed mental health structures such as hospitals, hostels, community mental health wards, to name but a few and the fear of harm and self-harm still prevent society to fully accept and adopt the integrative principles of Care in the Community (Muijen 1993).

The gradual elimination of segregating lines could be enabled with the initiation of the discussion about accessibility and mental health as it shifts the perspective from clearly-defined purpose built environments to integrated places in the community. The author supports that knowledge and understanding of mental illness would promote the integration of mentally ill people in our societies. According to a service user, stigma and its subsequent segregation results from fear that results from lack of knowledge and understanding (Tobias 2015). According to scientists, mental illness is among the diseases where we have the least knowledge and understanding (Christensen et al 2009, The Economist Intelligence Unit 2014). Changing our perspective about it, and incorporating what it is already there as a theoretical model and as a recognized medical field, i.e. the principles of Care in the Community, could be a first step for the accessibility and the better integration of mentally ill people. 
Inclusive Design and Mental Health: Policy and legislation challenges from the perspective of social inclusion

This paper argues that strategic planning, legislation and broader built environment interventions could play an important role towards the social integration of mentally ill people. Also, the segregative aspect that mental illness affects only a limited number of the population, compared for example to mobility or old age, needs to be addressed as a myth and it has to be reviewed as opposing to the principles of Community Psychiatry and as cultivating closed institutions in the community. The paper addresses both points. First, as it stressed the importance of considering mental illness as a subject affecting society as a whole. Then, it will demonstrate new strategies that would help include mental illness in the society. The later will be argued with the upcoming Greek legislation on the subject and how it challenges the existing broader framework of building permits.

\section{A Case study on changing the game}

Next we will explore a very interesting case study as an example of a shift of policy from segregative to integrative, as it derived from a combination of causes that will be explored later in the paper. That is the example of Greece, the country who first accepted and protected the mentally ill as a valid part of society, 3.000 years ago, for their God-sent abilities. However, modern Greece is a European Country that started its "Psychiatric Revolution" in the mid 80s and still presents a quite low placement according to the Mental Health Integration Index, being $28^{\text {th }}$ out of 30 countries, followed by Romania and Bulgaria (The Economist Intelligence Unit 2014). The economic crisis is amongst the reasons for this placement. Yet, despite the fact that employment, for which Greece was the $24^{\text {th }}$ out of the 30 countries, is having a great influence on that Index and Greek unemployment is one of the highest in Europe, the poor access to health services, stigma and access to a stable residential environment prevent the country from achieving a better position in that ranking. As a case study, Greece sheds light in a model of de-institutionalisation that has been already applied in a European Union country with limited resources and the lessons learned could have great values to many European and European Research Area countries that start their de-institutionalisation now, such as Bulgaria, Romania and other Balkan countries or Turkey. It could also be of relevance to Israel, that is now shifting its mental health care provision from public to run by charities. However, aspects of this shift towards integration can be also relevant even in the most developed from a psychiatric-provision-perspective countries such as the UK that is considered among the most advanced countries on the subject, as even these have a long way to go for a true integration and as several of the so called community based 
wards are still in hospital premises (Care Quality Commission 2015, Chrysikou 2014).

To counter the lagging of the Greek psychiatric integration, the country with the support of the European Commission, is exploring and employing a series of strategies to improve the provision of care under the Psychargos Program, i.e., a national plan that started at 2000 for the closure of the big institutions and the provision of a network of services in the community. One of the interventions of Psychargos has been the identification of problems in the licensing of all types of community mental health facilities and as a next step altering the licensing procedures, updating the building and technical equipment requirements. This attempt was based on two main objectives. The first objective constituted the design of a simpler and fairer licensing procedure. The second, that occurred as a result of the first, involved the redesign of a set of national guidelines for each facility type that would promote the support and integration of mentally ill people in the community, as European Commission indicated.

The methodology designed and used to explore the main problems that the facilities encountered constituted two main parts. The first, involved a first identification of problems regarding the issue of licenses to operate for non-for-profit mental health service providers. These are the equivalent for Greece of Mental Health Trusts, they operate at the third sector of the economy and provide the vast majority of non-hospital care. This was conducted by the Support Mechanism for the Mental Health Services and their Networking and Cooperation at a Sectoral and Peripheral level. The expertise also took into account the available reports of the Inspection Committees, of the Fire brigade and the Greek Legislation.

The second part of the methodology comprised approaching all service providers and asking their input as well as literature review on evidence and international best practice. Also, the main findings of the first part of the methodology were incorporated in order to produce a report on the situation and a set of actions that would set the basis of producing new national guidelines. The stage involved the design and administering of a questionnaire of 29 questions regarding the process of acquiring building permits and licenses to operate of the mental health facilities. This was then distributed to all 116 facilities to fill by the Support Mechanism. These comprise 53 care homes, 28 day centres, 3 mobile units, 23 protected apartments and 5 hostels. Some of these have been operating for more than 20 years, yet at the time of the research a $10 \%$ of the facilities had their operating licences still pending. There were also the psychiatric departments of the general hospitals or other types of facilities, including day centres, hostels or care homes, located inside hospital campuses, but these have been excluded. The Support Mechanism sent the completed 103 questionnaires back to the researchers for evaluation. This methodology aimed at the evaluation of the situation in Greece and would also provide an understanding on how the Trusts and in particular the facilities 
Inclusive Design and Mental Health: Policy and legislation challenges from the perspective of social inclusion

themselves perceive the problems they faced. It would also shed some light on what they perceive as potential solutions.

\section{Findings}

A key finding of the questionnaire that was sent to the facilities was that the people involved in the running of the facilities expressed the need to simplify the planning permit procedures. As building permits did not have implications for the mobile units and the apartments, here we will focus on the other three types of facilities, i.e., the care homes, the day centres and the hostels. Regarding permits $47 \%$ encountered a series of problems with strong financial and budgeting implications and an additional $8 \%$ did not specify the source of difficulties. $36 \%$ replied that the planning permit procedures affected negatively their timescale and budgeting and added to their total costs. An additional $10 \%$ mentioned that they encountered significant delays with considerable financial implications to their budget. $14 \%$ encountered problems with the site plan and the permitted uses. Additionally, $57 \%$ of the total sample proposed support measures, including the creation of a support service for the planning and the licencing or insisted on the need to reduce the time required for acquiring the licenses. This was in agreement with earlier findings of the Mechanism during the consultation period and the inspections associating complicated and time consuming procedures to difficulties of the facilities of acquiring the necessary licences. Therefore, the expertise indicated as one of the main reasons for the lack of adequate number of community mental health facilities in Greece the complexity and the length of licensing procedures. This was either preventing. Trusts to expand and open new facilities or led them to operate in an obscure status, where the facilities where not fully compliant to the licensing procedures, yet the lack of alternative provisions and the lose control mechanisms enabled them to operate. As a result, the main aim of the project became the establishment of a realistic platform that would enable the facilities to operate in a legitimate way.

One of the biggest problems that was identified in the existing facilities was the change of use: it proved too lengthy and costly as a procedure or occasionally too complex to be achieved at all. Plus, there was a number of facilities who were located in areas where the change of use could not be granted at all. In that case, $67 \%$ of the facilities would either have to compromise with expensive to rent property, or property outside their catchment area, often institutional looking and stigmatizing, or the fact that they did not get their license yet and until the use requirements changed, could not get it at all. As substantial pressure both from European commission that did not approve of asylums catering for mentally ill people (ECITE 
1995) and also from an actual practical need, as even at this status of operation the facilities provided a necessary service and if they stopped to operate the residents would be forced to return either to asylums or to the streets, a practical solution had to be found without any further delays.

As it would be practically impossible to change overnight the dysfunctional and highly beaurocratic system of planning permissions (Economou et al 2007, Manolopoulos 2011) the alternative of simplifying the use requirements was examined. Thus, an initial solution was proposed by the support mechanism and was implemented with the decree of Protocol Number 107931/22-11-2013, decree with Protocol Number 107933/22-11-2013. Under these two decrees, community mental health facilities that served as accommodation, such as hostels or care homes, could be facilitated in residential areas and any property that its use was residence. Similarly, day centres did not require any more properties that were built under the healthcare use, but could be hosted in any property characterised as offices. Compared to the health or welfare uses that existed before this uses were much simpler as they allowed flexibility, increased the choice of available premises and decreased the requirements in terms of structural engineering. This of course, solved most of the problems prohibiting the opening of such facilities in Greece. Despite the change of requirements for use though, some problems remained. The most significant in terms of licensing, was the lack of the local Fire Brigade departments to recognize the adequacy of residential requirements as adequate for the function of psychiatric hostels, care homes or day centres. $33 \%$ had to make changes and $21 \%$ of the total sample found it rather difficult to comply, resulting in considerable delays. This was reasonable, especially if one took into account issues related to the particular function of these facilities. They accommodate more people than an ordinary family home, there is an increased dangerousness due to pathologies involved and there is a greater difficulty regarding evacuation in cases of emergencies compared to normative population.

From all the above, it became clear that there was a need to retain the simplified licensing procedure, without losing the qualitative and therapeutically necessary attributes of space, that a health related use would incorporate. The typologies of residence and office could not be fit for those purposes, as over simplistic. This was in agreement with predeceasing research findings (Chrysikou 2013) on the inadequacy of domestic typologies to fully cater for the needs of mentally ill people at acute stage or at the early stages of rehabilitation. Indeed, there were issues that rose from the co-habitation of a substantial number of people that at the same time had increased care needs. Basic needs, such as safety were compromised but the same could be said for the ability to function independently (competence) as well as users' personalisation and choice. Also, once more the oversimplifying of requirements as it were expressed in residential typologies could by no means prevent institutionalisation. The research also indicated substantial problems in 
Inclusive Design and Mental Health: Policy and legislation challenges from the perspective of social inclusion

evacuation plans, increased wear and tear due to tough use and inadequately tough materials and fixtures associated with residences, increased needs for security and institutional environments that provided very limited stimuli to users. Contrary to the initial aspirations, they resulted in the creation of small scale asylums in the community.

As solution to the problems deriving from oversimplification of uses and the lack of an adequate framework of guidelines for mental health facilities, was proposed the introduction of detailed guidelines referring to the specific typologies. Thus, all the problems deriving from the choice of land would be prevented allowing more choice of potential properties, saving time and costs, yet then adaptations would be necessary according to purpose. That way, the limitations that used implied could be still eliminated, but the quality would be safeguarded by fit for purpose guidelines that facilities would have to meet prior to operation. It is beyond the scope of the paper to go into more detail about the features of the guidelines, however, it is important to state that they contained all the building traits (together with all other specs) that more specific uses would mean. At the same time the flexibility of uses (residences and offices) in terms of planning permits enable a higher degree of integration of the facilities in the community as residential facilities could now be built in residential only areas and the local community could not raise legitimate NIMBYism claims for their closure. This, was not as we explained the main motive for this change of use but it was certainly a very integrating element that came as a result. In that sense, even in countries that planning permits are straightforward and easy to get, the flexibility in uses relating to mental health and the ability of the facilities to be located even in purely residential areas, would be a considerable step towards their integrations as well as the accessibility of mentally ill people, as they will be enabled to access normal neighborhoods again.

Finally, another topic that rose in the legislation, was again related to the location of the facilities. According to rehabilitation theories, community mental health facilities have to be located in the community they serve. Greek legislation enabled the facilities to operate in close proximity to the community (FEK 2000). This resulted in existing facilities being located outside the population they served and sometimes segregated from the urban grid, in the fields. This was picked up and altered changing the requirement from close proximity to within the catchment area they serve, as obligatory. This aspect appears more restrictive, as it puts the proximity as inadequate and the centrality as the optimum location, yet it means a lot in terms of accessibility and breaking the barriers of NIMBYism. The new legislation might minimise the chances for out of site out of mind situations that the previous 'close to the catchment area' phrasing would enable. Mentally ill people should live and be treated within the community they belong. 


\section{Conclusions}

The increased numbers of mentally ill people will eventually create the pressure for facilitating the existing need of caring for these people in the community. This will mean that society will have to become able to manage dangerousness within its core. The ultimate way of this acceptance is architecture accommodating elements necessary for the universal accessibility of mental illness in generic guidelines as a result of demographics and anti-stigma campaigns, very similarly to other forms of disability and the needs of older people after the pressure of the baby-boomers. Right now, this is a future goal rather than a current reality.

Therefore, a whole range of strategies, short-, mid- and long term, as well as a range of products, from low or high-tech and from specialised to generic architectural guidelines, software applications, workplace and accommodation solutions, referring to all range of spaces, from physical to virtual, including even sectors such as gaming, entertainment or tourism to cater for the whole spectrum of a persons' needs. This means a paradigm shift for the design for mental illness as one that is happening entirely in the society, improving primarily the quality of life of the people living with the illness at some-point in their lives but also of their families and carers, who also suffer of high burnout rates as well as the effects of stigma. The broadest impact will be, however, for our entire society as it means that one of the most characteristic types of total institutions, i.e. the mental institutions (Marcus 1993), will become more and more obsolete. This reality is, in short, linked to a more adaptive and a more responsible society that does not need walls of asylums (small or big) to contain its risks.

Acknowledgements: Dr Evangelia Chrysikou is Chief Investigator of the project Planning and Evaluation Methodologies for Mental Healthcare Buildings (PEMETH). Dr Chrysikou's research is funded by the European Union's Horizon 2020 research and innovation programme under the Marie Sklodowska - Curie Grant Agreement No 658244.

\section{References}

Alzheimer's Society Report (2013) 'Building dementia-friendly communities: A priority for everyone', London: Alzheimer's Society

Care Quality Commission (2015), 'Right here right now: People's experiences of help, care and support during a mental health crisis' 
Inclusive Design and Mental Health: Policy and legislation challenges from the perspective of social inclusion

Chartokolis, P. (1989) 'Introduction in Psychiatry'. $2^{\text {nd }}$ ed. Athens: Themelio Publications

Christensen, C. M., J.H., Hwang, J., (2009), 'The Innovator's Prescription'. New York: McGraw-Hill

Chriswick, D. (1995) 'Dangerousness', Seminars in Practical Forensic Psychiatry, Edited by Derek Chriswick \&Rosemarie Cope, The Royal College of Psychiatrists. Glasgow: Bell and Bain Ltd

Chrysikou, E. (2013) 'Accessibility for mental healthcare'. Facilities, 31 (9/10), p. 418-426

Chrysikou, E. (2014) 'Architecture for psychiatric environments: environments and therapeutic spaces'. Amsterdam: IOS Press

Chrysikou, E., Symvoulakis, E., Lionis, C., (2014) 'Home environment design and frailty: a proposal to increase impedance. WONCA, 19 th WONCA EUROPE Conference 2014'. Lisbon, 2-5 July.

Darcy, S., \& Dickson, T. (2009) 'A Whole-of-Life Approach to Tourism: The Case for Accessible Tourism Experiences'. Journal of Hospitality and Tourism Management, 16(1), $32-44$

Dementia - friendly Hampshire Toolkit (2012) 'Making Hampshire a dementia-friendly county. Finding out what a dementia friendly community means to people with dementia and carers'

Diebolt, E. (1997) 'De la quarantaine au quarantaine: histoire de foyer de postcure psychiatrique de 1' Elan'. Paris: L' lan Retrouve

ECITE (1995) 'Parts from the Report conducted on behalf of EC, on the visit in psychiatric hospitals, Autumn 1995', Tetradia Psychiatrikis (psychiatric notebooks), 54, April-June: pp. 23-33

Economou, D., Petrakos, G., and Psychari, Y., (2007) 'Ashgate, National Policy responses to urban challenges in Europe', Edited by Leo van den Berg, Erik Braun and Jan van der Meer. European Institute for Comparative Urban Research (EURICUR), the Netherlands: Erasmus University Rotterdam

FEK (2000) 'YA No Y5v/1962/21-9-2000' FEK B' 1268/19-10-2000, article 7, paragraph 5, as it was amended and validated

Foucault, M. (1972) 'Histoire de la folie a l'age clasique'. Éditions Gallimard

Georgiou, G., Vargopoulos, D., and Hatziioannou, A. (1993) 'The psychiatric problem analysis from prehistoric era until early Renaissance', Galen, 35 (6): pp 631-39

Gilburt, H., Peck, E., Edwards, N., Naylor, C., Ashton, B., (2014), 'Service transformation: lessons from mental health,' London: King's fund

Glascow, N. (2000) 'Transportation transitions and social integration of Nonmetropolitan Older persons', Social Integration in the second half of life, edited by Karl Pillemer, Nina Glascow, Phyllis Moen, Elaine Wethingon, chapter 4. United States of America: The Johns Hopkins University Press, pages 108-132

Gomez JI, Langdon JA, Bichard JA, and Clarkson PJ (2014) 'Designing accessible workplaces for visually impaired people' in Inclusive designing. Joining usability, accessibility, and inclusion, 269-280

Langdon PM, Lazar J, Heylighen A, Dong H, (2014) 'Inclusive designing. Joining usability, accessibility, and inclusion' Springer, London, 978-3-319-05094-2

Madianos, M. (1980) 'Social Psychiatry: historical review, definition and ideology', Encephalos 17: pp159-165 
Maisel, J. (2010) 'The State of the Science in Universal Design: Emerging Research and Developments'. State University of Ney York at Buffalo, USA: Benthan science publishers Manolopoulos, J. (2011)' The looting of the Hellenic Republic by the Euro, the Political Elite and the Investment Community'. London: Anthem Press

Markus, T. (1993) 'Buildings and power: freedom and control in the origin of modern building types'. London: Routledge

Muijen, M. (1993) 'Mental health services: what works? in Weller and Muijen (eds) Dimensions of community mental health care'. London: Saunders

Priebe S, Badesconyi A, Fioritti A, Hansson L, Kilian R, Torres-Gonzales F, Turner T, Wiersma D (2005). 'Reinstitutionalisation in mental health care: comparison of data on service provision from six European countries'. BMJ, vol 330, no 7483, pp 123-6

Riley, R. W. (1999) 'Schools as Centres of Community' (Remarks as prepared for delivery to the American Institute of Architects). Washington, DC: U.S. Department of Education

Synchrony Financial (2014) 'Balancing Multi - Generational Retail Strategies. Winning over Millennials without losing Boomers'

The Economist Intelligence Unit (2014), 'Mental health and Integration. Provision for supporting people with mental illness: a comparison of 30 European countries'

Tobias, S.\&T. (2015) 'In-patient Bedroom Design - The User Perspective \& The Dragon Café' oral presentation at session 'Creating Madlove - A Designer Asylum - The Vacuum Cleaner', at 11.30 - 12.15 a.m. on the 19th of May. Design in Mental Health Conference 2015. Birmingham, 19-20 May

Vostanis, P. (1989) 'Re-establishment of the mentally ill', Encephalos, 26: pp 97-1984

WHO World Health Report 2001 (2001) Mental Health: New Understanding, New Hope. Geneva: World Health Organization

WHO Regional Office for Europe. Mental Health Declaration for Europe. (2005) WHO European Ministerial Conference on Mental Health: Facing the Challenges, Building Solution; 12-15 January 2005; Helsinki

WHO Regional Office for Africa (2010) A situation analysis of mental health in Somalia. Somalia Liaison Office

WHO, (2013) Prevention of mental disorders and suicide. [online] Available at: http://www.euro.who.int/en/what-we-do/health-topics/noncommunicable-diseases/mentalhealth/activities/prevention-of-mental-disorders-and-suicide [Accessed 22 July 2013]

Wu, Charles F., and Joseph Beyer (2014), 'Harvard Business School Case 215-003', July 2014. (Revised May 2015.)

Zeisel, J. (2010) 'I'm still here - A breakthrough approach to understanding someone living with Alzheimer's', Great Britain: Piatkus 